\title{
LA GRAMATICA DE LA ACADEMIA DEL SIGLO XVIII
}

Aunque los primeros trabajos de la Academia en su empeño por estudiar el castellano no apuntaron al campo gramatical, tampoco abandonó este aspecto de la lengua. Sus primeros esfuerzos se dirigieron a recoger el vocabulario y como fruto tenemos el magnífico Diccionario de Autoridades. Más tarde aprovecharía la gran cantidad de materiales acumulados para el Diccionario y daría a la Gramática el carácter normativo que hasta entonces no había sido el predominante en los tratados de gramática española. Vamos, pues, a intentar un acercamiento a esta gramática y estructuraremos estas notas en tres apartados. Primeramente, narraremos la historia externa de la elaboración de la gramática teniendo como guía las actas de las sesiones de la Academia ${ }^{1}$. En segundo lugar, veremos los cambios doctrinales que hay entre las tres primeras ediciones de la gramática y la cuarta, todas del siglo xvirI. Por fin, intentaremos situar la gramática de la Academia dentro de los estudios gramaticales anteriores. Aunque nuestro estudio se va a centrar en las gramáticas, no hemos olvidado un repaso a las ideas gramaticales contenidas en los diccionarios de la Academia del siglo XVIII ${ }^{2}$.

1 Debemos expresar nuestro agradecimiento a D. Rafael Lapesa por su amubilidad al concedernos el permiso para la consulta de las actas.

- Los diccionarios de la Academia del siglo xvm son: Diccionario de Autoridades, Madrid, I 726-1739, 6 vols. Hay edición facsimil, 3 vols., Madrid, Gredos, 1963: Diccionario de la lengua castellana. Reducido a un tomo para su mas fácil uso, Madrid, Joaquín Ibarra, 1780; segunda edición, I783; tercera edición, I791. 
Ia primera edición de la Gramática de la Academia aparece en I77I. Pero esto no quiere decir que no se hubiese intentado antes la redacción de una obra de este tipo. En efecto, en la sesión que tuvo lugar el martes 7 de julio de I767 señala el Director de la Academia la necesidad de una Gramática y declara que "habiéndola emprendido tiempo ha, y hecho sus individuos muchas y muy útiles observaciones, sería lástima que queden sin fruto y en olvido». Pero en aquellas fechas andaba la Academia ocupada en el aumento y corrección del Diccionario y encarga a D. Juan Trigueros y al P. Juan de Aravaca el estudio de los papeles que se guardaban en la Secretaría ${ }^{1}$. Un año más tarde ya había visto Trigueros los papeles que se le habían encargado y había redactado el capítulo del nombre, pues en el acta del jueves 2 I de julio de 1768 se lee que "en cuanto a la gramática expuso el Sr. Trigueros que después de haber visto los dos legajos de Disertaciones que se le entregaron hechas por diferentes sres. Académicos, los pasó al P. Aravaca y que habiéndolos vuelto a su poder, empezó a trabajar; y tenía ya evaquado lo perteneciente al Nombre que presentaría a la Academia antes de proseguir, por si en cuanto al método tenía que corregir o alterar». E1 jueves siguiente lee lo que tenía escrito y "acordó la Academia que yo prosiga esta obra siguiendo el método que lleba la parte que tengo trabajadan. (Habla en primera persona por ser Trigueros. entonces secretario.) Con el visto bueno de la Academia se dedica a la redacción del trabajo, que presenta ya terminado el día 30 de agosto. de 1770: "Presenté en la de hoy la Gramática que he formado de la Lengua Castellana... $\mathrm{Y}$ en su conseqüencia emepecé a leer este tratado, que se prosiguió hasta el fin del Cap. I.0 que trata del pronombren.

1 No hemos conseguido localizar en la Academia estos papeles que arrojarian bastante luz sobre el método empleado en la formación del cuerpo gramatical académico. Según Lázaro Carreter, en la elaboración de la Gramática "habian intervenido, a lo largo de medio siglo, numerosos académicos, entre los que destacaron Luzán y el docto humanista don Juan de Iriarte, que contribuyó además a su elaboración con una serie de comunicaciones recogidas en el segundo tomo de las Obras sueltas (1779). Vid. Las ideas lingütsticas en España durante el siglo $X V I I I$, en $R F E$, anejo XLVIII, Madrid, I949, p. I82. También se hace alusión a esta contribución de los académicos en el prólogo de la Gramática, compuesto, como veremos, por el mismo don Juan Trigueros: a... se ha valido la Academia para componer esta Gramática. de las que han publicado otros autores propios y extraños: de un considerable número de disertaciones que han compuesto sus individuos; del copioso caudal que encierra el Diccionario, y de los demás medias que le ha dictado su deseo de servir al Públicon. Cf. Gramática de la Lengua Castellana, Madrid, Joaquin de Ibarra, I77r, prólogo, IV. 
A1 mismo tiempo, señala que devolvió los dos legajos. La lectura del trabajo de Trigueros se prolonga hasta el día 23 de octubre de 1770 . Siguen algunos trámites ${ }^{1}$. Y, por fin, el jueves 7 de marzo de I77r, dice Trigueros en el acta de la sesión: "Hice presente un exemplar impreso de la Gramática Castellana, y la Academia acordó que se enquadernen desde luego los exemplares de ella que fueren necesarios». Esta es la historia de la elaboración de la primera edición de la Gramática, quedando cumplido un antiguo deseo de la Academia. Teníamos que haber visto los dos legajos de que se sirve Trigueros para saber hasta dónde llega su labor personal. De todas formas, pasaron más de tres años desde que se le encarga el trabajo hasta que termina su lectura en sesiones acadénicas.

Pero apenas unos meses después de su aparición ya se necesitan más ejemplares y el martes 16 de julio de $\mathrm{I} 77 \mathrm{I}$ se toma el acuerdo de solicitar el permiso para la reimpresión "con las correcciones y adiciones convenientes». Será, sin embargo, un año después, el 2 de julio de I772, cuando Trigueros anote en las actas: "Habiendo manifestado el Sr. Tesorero en la Junta anterior que se iba acabando la primera impresión de la Gramática traxe un exemplar con algunas leves correcciones y adiciones, y leídas en la Academia acordó lo que tuvo por conveniente, y que con ellas se procediese a la reimpresión, y se sirvión encargarme que cuidase de ella" ${ }^{2}$. Pero, por enfermedad de Trigueros, se encarga el Sr. Angulo de los demás problemas, y el 24 de noviembre se aprueban las cuentas de la reimpresión presentadas por Joaquín Ybarra, impresor de la Academia.

Nuevamente el $3 \mathrm{I}$ de marzo de I780 notifica el tesorero que quedaban pocos ejemplares de la "Gramática Castellana" y la Academia "acordó que se reimprima y se tiren dos jornadas y para la corrección nombró al Sr. Huerta" ${ }^{3}$. Ninguna alusión más se encuentra en las actas.

1 El 23 de octubre se acuerda pedir permiso al rey para la impresión, y el permiso fue concedido el $I_{7}$ de diciembre de 1770 , como consta en la sesión del día siguiente. El I $_{5}$ de enero de $\mathrm{I}_{77 \mathrm{I}}$ lee Trigueros el prólogo y la dedicatoria y pone a su cuidado la Academia kel encargo de corregir la impresión de esta obra y lo demás que pertenezca a ella».

2 Las leves correcciones y adiciones a que alude Trigueros son, en efecto, muy pequeñas. Consisten en añadir a los verbos irregulares de la tercera conjugación los verbos "conducir", "asir", "bendecir" y "contradecir", con sus respectivas conjugaciones. Añade también una lista de participios irregulares que no. terminan en -ado, ni en -ido. $Y$ añade, por fin, a la lista de las preposiciones la preposición "cada", con sus usos. En total son ocho páginas más que en 1771 ..

a Don Juan Trigueros habia muerto en 1777 , según se notifica en la sesióm del $\mathrm{I}_{4}$ de octubre de dicho año. 
a esta reimpresión, que aparece en $\mathrm{I} 78 \mathrm{I}$ y sin ninguna modificación respecto a la de 1772 con la que coincide hasta en el número de páginas.

La gestación de la última edición que se hace en el siglo xvir de la Gramática empieza el 9 de febrero de I786: "Habiéndose tratado sobre si se había de corregir la Gramática antes de hacer otra impresión, acordó la Academia que los sres. de la segunda sala examinen los puntos que necesitan de corrección, y den cuenta en Academia plena para resolver sobre ello». En abril de 1787 se presentan las correcciones y adiciones, y se acuerda examinarlas "suspendiendo entre tanto el trabajo del Diccionario, lo que efectivamente se empezó a hacer desde esta Junta, y se leyó hasta el artículo 3 pag. 8». Sin embargo, la preparación de estas correcciones no es continua, pues pasan casi diez años hasta que en 1796 aparece por fin esta edición ${ }^{1}$. Y así, el jueves 7 de enero de 1796 escribe el secretario: "Di cuenta que de casa e imprenta de la viuda de Ybarra se habían trahido a estos almacenes 150 exemplares marquilla de la quarta edición de la Gramática española, y la Academia teniendo presente lo que anteriormente había conferenciado con el Sr. Director de que convendría regalar un exemplar a las personas Reales, y los cuerpos y sujetos a quienes es regular, por haberse anımentado y corregido notablemente...». Es de destacar el largo período de tiempo dedicado a la elaboración de esta edición y el hecho de que apareciera notablemente aumentada y corregida. ¿Hubo gran discusión en admitir las adiciones y correcciones? Por las actas no lo sabemos. Pero alguna polémica debió de haber, ya que nada más àparecer llegan algunas observaciones. Dice el secretario el 22 de marzo de 1796: "Leí un papel con unas ligeras observaciones sobre los capítulos de nuestra

1 Hay alusiones dispersas en las actas, pero no está claro que todo el tiempo se dedicara a corregir la Gramática. Así el ig de abril de 1788 se dice que "se continuó el examen de las correcciones y adiciones de la Gramática hasta concluir la lista de los verbos, participios, adjetivos y adverbios que rigen preposiciones". En 1793 se reemprende la lectura, según consta en el acta del 4 de julio: "En conformidad de lo acordado anteriormente se empezaron a leer las correcciones de la Gramática y se leyó hasta la regla 6 , de los géneros y pretéritos». Se sigue corrigiendo hasta el 29 de agosto, llegando a la página 243. En esta fecha se interrumpe la corrección, que se reanudará el $\mathrm{r}_{3}$ de mayo de I794: «Se empezó a leer la Gramática y se leyó hasta la última regla del artículon. Se concluye su lectura el 9 de septiembre de 1794 . Incluso en 1788 tuvo la Academia que acordar una reimpresión de 1.500 ejemplares de la edición anterior, sin alterar nada, porque usi se aguarda a que se concluyan las correcciones que se están haciendo, según el corto número que hay de ejemplares, llegaria a faltar enteramentes. (Acta del I de julio de r788.) 
Gramática, y la Academia determinó que se pasasen al Sr. Valbuena y encargó a los demás Académicos hiciesen lo mismo con las que encontrasen, y les ofreciese su lectura y reflexión".

$\mathrm{Y}$ esto es todo lo que sabemos sobre la formación de la Gramática por las actas académicas. El proceso se puede resumir en tres etapas. Una primera de elaboración colectiva con abundantes comunicaciones de académicos, recogidas en los papeles que no llegaron a publicarse. I a segunda consistió en la labor individual de D. Juan Trigueros, que aprovechó los papeles anteriores y cuyo fruto fue la edición de la Gramática en $\mathrm{I} 77 \mathrm{I}$ y las dos siguientes de $\mathrm{I} 772$ y $\mathrm{I} 78 \mathrm{I}$. Por fin, la larga etapa de corrección colectiva que conduce a la cuarta edición en I796, con notables diferencias respecto a las anteriores ${ }^{1}$.

Vamos a intentar un resumen del contenido de la Gramática, señalando las principales diferencias que hay entre las tres primeras ediciones y la cuarta. Al mismo tiempo, echaremos un vistazo a los diccionarios y sus diferencias gramaticales respecto a las otras obras.

Consecuente con la concepción normativa que la Academia tiene de la gramática, se define ésta como "el arte de hablar bien». Y esta definición no cambia en las cuatro ediciones ${ }^{2}$. Pero ya en la división de la gramática surge la primera divergencia entre las tres primeras ediciones y la cuarta. En las primeras se diferencian dos partes: «la primera trata del número, propiedad y oficio de las palabras: la segunda del orden y concierto que deben tener entre sí para expresar con claridad los pensamientos» ${ }^{3}$. Distinguen solamente, pues, morfología y sin

1 Las Gramáticas de la Academia del siglo XvIII son: Gramática de la Lengua Castellana, compuesta por la Real Academia Española, Madrid. Por D. Joachin de Ibarra, Impresor de Cámara de S. M., I77I; segunda impresión, I772; tercera impresión, 1781; Quarta edición corregida y aumentada. Con superior permiso por la viuda de don Joaquín Ibarra, impresora de la Real Academia, Madrid, I 796.

- En la Gramática de la Academia de r93 se sigue definiendo en términos. parecidos: "Gramática es el arte de hablar y escribir correctamente». Cf. Gramática. de la Lengua Española. Nueva edición reformada, Madrid, Espasa-Calpe, I93I. p. 7 .

3 Gramática, I77I, pp. I-2. Hoy Roca Pons dice: "La Gramática, en un sentido estricto y riguroso, está formada por lo que tradicionalmente viene llamándose morfologia y sintaxis». Cf. Introducción a la Gramática, Barcelona, Vergara, I960, I, p. I6. 
taxis. Por el contrario, en 1796 se enumeran como partes de la gramática, la ortografía, la analogía, la sintaxis y la prosodia. Bien es verdad que se trata de una división teórica ya que sólo estudia la morfología y la sintaxis, omitiendo la ortografía uporque anda en tratado separado, y la Prosodia, por no haber fixado todavía la Academia las reglas de la verdadera pronunciación de las voces castellanas»" ${ }^{1}$.

Tampoco concuerdan las gramáticas de la Academia en el concepto de palabra o parte de la oración, y mientras en I77 I se dice que palabra "es lo mismo que voz o dicción, como: cielo, tierra, santo, docto, leer, escribir», en 1796 se impone una tendencia logicista, al afirmar: "Todas las palabras de que nos valemos para declarar nuestros pensamientos son, y se llaman partes de la oración” ${ }^{2}$. ¿Y cuáles son las partes de la oración? La Academia observa en el Prólogo que no hay unanimidad entre los autores consultados: "Hay entre estos tres autores (Nebrija, Patón y Correas) la misma variedad de opiniones que se observa en otros en quanto al número de las partes de la oración. Nebrixa establece diez: Patón cinco: Correas tres». Y, tomando una postura original, dice: «La Academia que tiene por verdaderas partes de la oración las palabras que Correas agrega al nombre y al verbo, y las que comprehende en la partícula, entiende que las partes de la oración son nueve» ${ }^{3}$. Ahora si hay unanimidad en las cuatro ediciones, y las partes de la oración son: nombre, pronombre, artículo, verbo, participio, adverbio, preposición, conjunciớn e interjección ${ }^{4}$. No concuerda con esta enumeración ninguno de los diccionarios de la Academia del siglo xvIII, pues en ninguno de ellos se cita el artículo como parte de la oración. Y de las siguientes palabras hay que deducir una confusión del artículo con el pronombre: "Además de estos artículos hai el de Le y Les, el que se usa

1 Gramática, 1796, pp. I-2. Hoy la Academia sigue diviendo la Gramática en las mismas cuatro partes.

- Gramática, I77I, p. 2; I796, p. 3. Citamos por la Gramática de I771, pero ha de entenderse que el contenido es el mismo en las ediciones de 1772 y 178 . El logicismo en la definición de palabra está representado también en la Gramática de la Academia de r93r: "Llámase palabra, vocablo, voz, dicción o término la silaba o conjunto de silabas que tiene existencia independiente para expresar una idea", p. ro.

s Gramática, I77I, prólogo, IX.

- Gramática, 1771, pp. 2-3; I796, pp. 3-4. Si comparamos esta clasificación con la actual de la Academia, vemos que se ha suprimido el participio como parte de la oración y el adjetivo se ha independizado del nombre. Vid. Gramática, I93I, p. ro. Bello es quien diferencia adjetivo y sustantivo como partes de la oración. Cf. Gramática, Buenos Aires, Sopena, 1964, p. 33. En la Gramática de la Academia se aceptan como partes distintas a partir de la edición de 1870 . 
en el caso que el Gramático llama Dativo, y es común al masculino y al femenino» ${ }^{1}$. Encontramos una innovación referente a las partes de la oración en la edición de 1796 . Consiste en la división que de ellas se hace en declinables e indeclinables: "Partes declinables son aquellas que varían en el modo de significar según y como se juntan con otras; y partes indeclinables son las que tienen un solo modo de significar acompañadas con aquellas a que pueden y deben juntarse. Las declinables son el artículo, nombre, pronombre, verbo y participio: las indeclinables, adverbio, preposición, conjunción, interjección’ ${ }^{2}$.

Pasando ahora a un análisis de cada una de las partes de la oración y comenzando por el hombre, advertimos diferencias entre la edición de I77I (nombre es "una palabra que sirve para nombrar las cosas») y la de 1796 , donde entra el concepto de adjetivo en la definición del nombre: "Nombre es aquella parte de la oración, que sirve para nombrar o llamar las cosas y personas, y para calificarlas» ${ }^{3}$. En los diccionarios predomina el carácter morfológico del nombre en su definición: "En la Gramática es la primera parte de la oración, que se declina por casos. Tiene géneros y no significa tiempon 4 .

El nombre engloba al sustantivo $y$ al adjetivo. No hay diversidad de criterios entre las gramáticas a la hora de caracterizar el sustantivo como "el que significa alguna sustancia corpórea, o incorpórea, como: hombre, árbol, piedra, entendimiento, ciencia, virtud. Subsiste por sí mismo en la oración, sin necesidad de que se le junte otra palabra que le califique» ${ }^{5}$. El nombre sustantivo es susceptible de ser dividido en varias clases. En primer lugar, puede ser común y propio. Fn la definición de nombre común y nombre propio tampoco hay diferencias entre las diversas gramáticas: «Nombre común, que también llaman apelativo, es el que conviene a muchas cosas; y nombre propio es el que no conviene sino a una" ${ }^{6}$. Todavía distingue la Academia otras

\footnotetext{
1 Diccionario de Autoridades s. v., articulo.

- Gramática, 1796, p. 18. Hoy persiste la división de las partes de la oración en variables e invariables en la Gramática de la Academia.

3 Gramática, 1771, p. 3; 1796, p. 18.

- Diccionario de Autoridades, s. v. nombre. Lo mismo en los otros diccionarios del siglo Xvirr.

- Gramática, 1771, pp. 3-4; I796, pp. 18 y 20. En los diccionarios se define el sustantivo basándose exclusivamente en su propiedad de estar solo en la oración: «el nombre que por sí solo puede estar en la oración, a distinción del adjetivo". Vid. sustantivo.

- Gramática, I77I, p. 4; I796, p. I9. En el Diccionario de Autoridades se llama apelativo "quando significa la especie», y propio es el unombre que expressa, o con que se da a conocer algún individuo de qualquiera especien. Las otras tres
} 
clases de sustantivos: primitivos, derivados (gentílicos o nacionales, patronímicos, aumentativos y diminutivos), colectivos, verbales, compuestos (y en 1796: compuestos de preposiciones que sólo tienen significado en la composición, y compuestos de preposiciones que tienen significado en la composición y fuera de ella), numerales (absolutos o cardinales y ordinales, que son adjetivos; y colectivos y partitivos, que son sustantivos) ${ }^{1}$. Hay que señalar el carácter caótico de todas estas divisiones en que no hay unidad de criterio, a no ser que se tenga por criterio el meramente enumerativo.

Otro cuestión relacionada con el nombre es la de sus llamados accidentes (género y número). En I77I sólo se reconocen dos géneros en los nombres: el masculino y el femenino. $\mathrm{Y}$ refiriéndose a los nombres epicenos se dice que "son de aquel género que señalan los artículos y adjetivos con que se juntan". Y lo mismo ocurre con los llamados anibiguos. Más aún: «Para conocer el género de los nombres no necesitamos recurrir a su significación, ni a su terminación, como en la lengua latina, que carece de artículos» ${ }^{2}$. Como vemos, su concepción del género es totalmente gramatical con independencia de criterios significativos. Pero en 1796 esta sana doctrina sufre una revisión, llegándose a afirmar que "los géneros son cinco: masculino, femenino, neutro, epiceno y común». Y más adelante se explica además el concepto de género ambiguo, con lo que ya son seis los géneros del nombre ${ }^{3}$. Para encontrar, sin embargo, una definición de la categoría gramatical de género hay que ir a los diccionarios, donde se explica que consiste en "la división de los nombres, según los distintos sexos, o naturalezas que significan y corresponden a los artículos que se aplican: como el, la, lo" ${ }^{4}$. De todas

ediciones del diccionario en el siglo xvmr coinciden en lo que se refiere al nombre propio, pero la definición de nombre común o apelativo es distinta: "Apelativo. Aplícase al nombre común que conviene a todos los individuos de una especie». Vid. apelativo, proprio.

1 Gramática, I77I, pp. 25-32; I796, pp. 33-5I. La Gramática de I931 distingue "primitivos y derivados; colectivos, partitivos y múltiplos; verbales; aumentativos, diminutivos y despectivos", p. 20.

2 Gramática, I77I, pp. 9-13.

3 Gramática, I796, pp. 7-8 y 68. Otra diferencia fundamental es que en esta Gramática se dan numerosas reglas para conocer el género de los nombres tanto por su significación como por su terminación. Véase pp. 51-62. La Gramática de I93 I distingue los mismos seis géneros que la de I796, dando igualmente reglas para conocerlos por su significación y su terminación, véase pp. 12-18.

- Diccionario de Autoridades, s. v. género. En los diccionarios del siglo XVIII, a partir del de I780, aparece el género "común de dos" y ullámase así el nombre substantivo, que baxo una misma terminación admite los dos géneros masculino 
estas caracterizaciones la más moderna y funcional es sin duda la de $177 \mathrm{I}$.

La categoría de número del nombre no presenta problemas. Se admiten dos números: singular y plural. Pero en lo normativo hay alguna pequeña diferencia que pone de manifiesto el distinto espíritu de la Gramática de 177 I y la de 1796 . Así, mientras en la primera se explica el número del nombre por su capacidad de combinación con el artículo, en 1796 se dan unas reglas basadas en la significación del nombre para justificar su número. Dice la Gramática de I77I: "Todo nombre que no admite sino el artículo el o la no tiene plural. Todo nombre que no admite sino el artículo los o las no tiene singular. Los nombres que admiten unos y otros artículos, tienen singular y pluralı ${ }^{1}$.

Mayores problemas presenta la discutida categoría de los casos. $\mathrm{Y}$ en este punto, la oposición entre la Gramática de I77I y la de 1796 es total. "Declinación en la Gramática latina, -se dice en I77I-, es la variación de un mismo nombre en diferentes casos, o terminaciones con distinta significación». $\mathrm{Y}$ más adelante: «Nuestra lengua no admite esta variedad de casos, o terminaciones en los nombres, y sólo conoce diferencia entre el singular y el plural de ellos». Y más aún: «Para expresar el diferente oficio que cada caso tiene en latín nos servimos de preposiciones" ${ }^{2}$. Comparemos ahora esta doctrina, que coincide con la actual sobre el caso en español, con la que adopta 1a Gramática en I796. La declinación se define como "el diverso modo de significar, que las partes declinables de la oración reciben de la unión con otras, o sin variar de terminación, salvo en distinto número, como los artículos, nombres y participios, o variando de terminación aun dentro del mismo número, como los pronombres y verbos». $\mathrm{Y}$ el caso se caracteriza así: "Estos diferentes modos de significar, o lo que es igual, la variación de significado que admiten las partes declinables de que hablamos, a excepción del verbo, se llaman casos". En castellano son seis: nominativo, genitivo, dativo, acusativo, vocativo y ablativo ${ }^{3}$. La semejanza con la teoría de la gramática latina salta a la vista. $Y$ en su deseo de ofrecer distintos tipos de declinación, a semejanza de las cinco declinaciones latinas, nos ofrece los siguientes paradigmas de declinaciones castellanas: sustantivo masculino de persona, sustantivo femenino de

y femenino, según el sexo que se quiere denotar, como el mártir y la mártirı. Véase común.

1 Gramditica, I77I, pp. I6 y 22-23; I796, pp. 5 y 22-24.

2 Gramatica, I77I, pp. 23-24.

- Gramditica, I796, pp. 5-6. 
persona, sustantivo masculino de cosa, sustantivo femenino de cosa, terminación neutra ${ }^{1}$. Creemos de mayor actualidad la doctrina de la primera edición. Hoy nadie habla de declinación en español, y a lo más que se llega es a admitir unos restos de declinación en los pronombres, que para Roca Pons «no responden a un sistema racionalmente necesarion ${ }^{2}$.

Ya hemos visto que el adjetivo no es considerado por la Academia del siglo xvirl como una parte independiente de la oración sino como una clase de nombre. En su caracterización no hay diferencias fundamentales entre las diversas gramáticas: se señala la función de unirse a un sustantivo para calificarle y la imposibilidad de estar solo en la oración sin un sustantivo expreso o tácito ${ }^{3}$. Se divide el adjetivo en positivo, comparativo y superlativo, y falta la clasificación en calificativos y determinativos, como se hace en $\mathrm{I}_{93 \mathrm{I}^{4}}$. Y esto es todo lo referente al nombre.

El artículo es definido en I77I por su función como indicador del género del nombre: "El artículo es una parte de la oración que sirve para distinguir los géneros de los nombres». El artículo da al nombre un valor definido o determinado, y también sirve para sustantivar infinitivos y partículas (adverbios y conjunciones). En I796 se especifica mejor su función deíctica y sustantivadora al definirlo como "una parte de la oración, que se junta sólo al nombre sustantivo o a otra parte que haga veces de nombre, para señalar y determinar la persona, cosa o acción de que se habla; y por lo mismo se llama definido o determinadoi. Pero una adición de signo negativo se produce en esta cuarta edición al presentarnos el paradigma de la declinación del artículo ${ }^{5}$. Según Roca Pons «sólo puede salvarse de la antigua doctrina su relación con el nombre en tanto expresa su género y número, pero esta no es ciertamente su misión esencial” ${ }^{6}$. Es decir, que si se puede salvar algo de la

1 Gramática, I796, pp. 25-28. Como es lógico, la Gramática de I93 I no habla para nada del caso como accidente del nombre sustantivo. Los diccionarios del siglo XVII tampoco aplican los conceptos de declinación y caso a la gramática española, con lo que se inscriben en la línea de $177 \mathrm{r}$.

- Cf. op. cit., I, pp. 218-219.

- Véase Gramática, I77 I, p. 6; I796, pp. I8 y 28-31. Los diccionarios tampoco ofrecen una definición distinta. En la Gramática de I93 I también se señala que "de la índole y oficios del adjetivo resulta que no puede estar solo en la oración, sino unido, o con referencia a algún substantivo", p. 27.

- Véase Gramática, I77I, p. 32; I796, p. 45; I931, p. 27.

- Véase Gramática, I77I, pp. 50-55; I796, p. 9. En los diccionarios se da una definición similar a la de r77I. Véase articulo.

- Op. cit., I, p. 205. 
concepción tradicional esto sería precisamente lo que enseña la Gramática de I77I. En cuanto al artículo indeterminado "un», no lo tiene la Academia por tal artículo. Sólo en el Diccionario de Autoridades se señala un valor de "un» semejante al de artículo: "un se usa también para dar fuerza, y energía a la expresión singularizándola, o ponderándola, y entonces se usa también con los verbos» ${ }^{1}$.

No hay divergencias entre las gramáticas de la Academia del siglo XviIr a la hora de definir el pronombre: «El pronombre es una palabra o parte de la oración que se pone en lugar del nombre, como: yo en lugar de Pedro: tú en lugar de Antonio» ${ }^{2}$. Ahora bien, sabido es que el Brocense rechaza los pronombres como parte de la oración basándose en que antes de que existieran los nombres particulares de cada cosa existirían los pronombres para designarlas de una manera general. La Gramática de I77I expone el problema en los siguientes términos: *algunos gramáticos pretenden al contrario, que el nombre se pone en lugar del pronombre; y fundan esta opinión en que las cosas son más antiguas que sus nombres, y antes que le tuviesen se denotaban por 1o que hoy llamamos pronombres, como: esto, aquello: Dicen que esta palabra "yo" no puede referirse a otra persona que a la que habla, como se puede diciendo Juan o Francisco, y que si las palabras que se ponen en lugar de nombres fuesen pronombres, lo deberían ser el Rey, el Duque, el Maestro, y lo serfan también el Orador, y el Poeta, que se ponen en lugar de Cicerón y Virgilio». No cabe duda de que estos argumentos debieron de impresionar a la Academia que, sin embargo, prefiere seguir la opinión común, cuando sigue: «Sin embargo de estas razones, se halla casi generalmente establecida la opinión contraria; y no mu-

1 Diccionario de Autoridades, s. v. un. Es la Gramática de Port-Royal la primera que habla de "un" y unna" como articulos indefinidos. Véase Grammaire générale et vaisonnée ou La Grammaire de Port-Royal. Edition critique présentée par Herbert E. Brekle. Facsimil de la tercera edición de 1676. Stuttgart, 1966, p. 52. Dos testimonios más de la aceptación de un como artículo indefinido hemos encontrado en el siglo XVIII español. El primero es de D. Ignacio de Campo en su Gramática de Cicerón y demás autores, Madrid, Manuel Román, 1772, donde dice: "Muchas vezes el romance "uno", o nuna", etc. son como "el, la, los", etc. que preceden (como artículos) a los substantivos, y en latín nada les corresponden, p. II2. El otro testimonio es de Pedro Contaut, que en su Gramática Española y Francesa, Madrid, Imprenta del Diario, r763, p. 32, dice: $\mathrm{El}$ artículo es esta dicción, un, una, uno... el... la... que se pone delante del nombre para señalar su género, su número y su caso". Hoy ni Amado Alonso ni Roca Pons admiten que un sea artículo.

- Gramatica, 177, p. 34; 1796, p. 63. Tampoco los diccionarios difieren de esta caracterización. 
dando el nombre al pronombre no se podrá mudar su definición: ni se adelantaría mucho en mudarla, porque esta y otras qüiestiones semejantes no son esenciales para saber mejor la Gramática" ${ }^{1}$. Vemos, pues, cierta preocupación por los problemas teóricos gramaticales, aunque luego se atenga a lo más práctico. Incluso parece desprenderse de las líneas de I77I cierto asentimiento a la teoría del Brocense, que no acepta por no ser la más general. Esta discusión no se plantea, sin embargo, en la cuarta edición.

Cuatro son las clases de pronombres que distingue la Academia del xvirr: personales, demostrativos, posesivos y relativos. Más adelante admite también como indefinidos "alguien», "nadie», "alguno»y "ninguno», pero no acepta pronombres interrogativos porque "los forma solamente el tono, y se reducen a los relativos” ${ }^{2}$.

Señala la Gramática de 177 I la diversidad de definiciones que se han dado del verbo, diciendo que "sobre su definición hay una variedad casi infinita de opiniones, dimanadas acaso de que unos han querido ceñirla a la existencia, otros a la acción y pasión, otros a la afirmación". Por eso la Academia prefiere reunir en su definición todas las notas. que se han dado del verbo, antes que elegir: "Una definición más extensa, dice, podría ser más exacta, y de menos inconvenientes: tal es la que aquí se propone». En efecto, de un criterio acumulativo procede la siguiente caracterización: «El verbo es una parte de la oración que sirve para significar la esencia, la existencia, la acción, pasión y afirmación de todas las cosas animadas, e inanimadas, y el exercicio de cualquiera facultad que tienen estas cosas, o se les atribuye» ${ }^{3}$. Como veremos, la definición está basada en criterios lógico-significativos. Fin I796 cambia algo el criterio seguido en la definición del verbo, y, además de suprimirse el planteamiento del problema de las distintas definiciones anteriores, se suprimen algunos de los rasgos de I77I y se añaden características morfológicas: "Verbo es una parte de la oración que significa

1 Cf. Constantino GaRcf., Contribución a la historia de los conceptos gramaticales. La aportación del Brocense, Madrid, Anejo LXXI de la RFE, 1960, p. 77. Y Gramatica, I77I, pp. 34-35.

2 Gramática, I77I, pp. 35 y 48-49. No hay diferencias en las otras ediciones ni diccionarios. En 1796 se rechazan además otras clases: «Si se hubieran de añadir clases de absoluto, de calidad, de quantidad, de identidad, de determinados, e indeterminados, y aun otras que han discurrido algunos gramáticos, en vez de aclarar más este punto, se pecaría en el extremo de la proligidad, y aun de obscuridad y confusión, que con el conato posible procuramos evitar", pp. 86-87.

8 Gramatica, I77I, pp. 56-57. 
la existencia, acción o pasión de las personas o cosas, con varias terminaciones de modos, tiempos, números y personas" ${ }^{1}$.

Tres clases de verbos son tenidos en cuenta por la Gramática de I77r: activos o transitivos, neutros o intransitivos y recíprocos. Pero los reciprocos deberían llamarse más bien pronominales: "Y además no hay verdaderos verbos recíprocos, pues para expresar la reciprocación hay que añadir otras palabras que la denotan como: unos a otros, entre sí, mutuamente" ${ }^{2}$. A estas clases se añade en 1976 la de los verbos sustantivos: "Verbo sustantivo es el que significa la existencia de las cosas o personas, como: ser, estar, haber” ${ }^{3}$. Más adelante hablan también de verbos regulares e irregulares, auxiliares, impersonales, defectivos, simples y compuestos.

En el siglo xviri la Academia señala que los modos del verbo son cuatro: indicativo, "el que indica o demuestra sencillamente las cosas»; subjuntivo, "el que necesita juntarse con otro verbo expreso o suplido que perfeccione el sentido de la oración"; imperativo, "el que sirve para mandar»; infinitivo, "el que no se ciñe a tiempos, números, ni personas, y necesita otro verbo que determine el sentido" ${ }^{4}$. La Gramática de 1796 señala estos mismos cuatro modos, igual que los diccionarios ${ }^{5}$.

Los mismos tiempos que en la realidad hay en la gramática: presente, pasado y venidero. El pretérito, según la Gramática de I77I, se divide en tres especies: a) imperfecto, acción presente respecto a otra pasada; b) perfecto, acción perfecta y absolutamente pasada, dividiéndose este tiempo en dos: I) próximo (perfecto), acción acabada con mayor proximidad al tiempo en que se refiere; y 2) remoto, menor proximidad (indefinido y anterior actuales; $c$ ) más que perfecto, acción pasada respecto de otra también pasada (pluscuamperfecto). En cuanto a los tiempos del subjuntivo, "a excepción del pretérito imperfecto, no tienen particularidad que notar, sino entender a las variaciones precisas de la conjugación" ${ }^{6}$.

1 Gramática, I796, p. 87. Los diccionarios, por su parte, dan una definición puramente morfológica, claramente emparentada con Nebrija: "Es una de las partes de la oración que se conjuga por modos y tiempost. Véase verbo.

2 Gramática, I 77I, pp. 58-60.

8 Gramatica, I796, p. 87.

- Gramatica, I771, pp. 62-63.

- En los diccionarios cambia la caracterización del indicativo: «El primer modo de conjugar los verbos, demostrando la acción, o pasión, según la diferencia de los tiempos presente, pretérito y futuro". Véase indicativo. En I93 I los modos se ven aumentados con el potencial, al tiempo que el infinitivo abarca también al participio y al gerundio. Véase Gramática, I931, p. 46.

- Gramática, 1771, pp. 63-66. 
En esquema, los tiempos del indicativo son:

$\begin{array}{ll}\text { Pretérito } & \begin{array}{l}\text { imperfecto (amaba) } \\ \text { perfecto próximo (he amado) }\end{array} \\ & \text { remoto (amé, hube amado) } \\ \text { pluscuamperfecto (había amado) }\end{array}$

Presente

Futuro

Se dedica seguidamente un capítulo entero al imperfecto de subjuntivo, cuyo uso se somete a seis reglas, y se diferencian tiempos simples o propios, "aquellos que sólo con una voz significan el tiempo", y tiempos compuestos o impropios, "aquellos que se expresan con más de una palabray. Ofrecemos a continuación un esquema de la conjugación tal como aparece en I77r:

\section{INDICATIVO}

Tiempos simples

Presente: amo

Imperfecto: amaba

Pret. perfecto: amé

Futuro: amaré
Tiempos compuestos

Pret. pecfecto: he, hube amado. Pluscuamperfecto: había amado.

Futuro: he de amar.

\section{SUBJUNTIVO}

Presente: ame

Pret. imperfecto: amara, amaria, amase

Futuro: amare
Pret. perfecto: haya amado.

Pluscuamperfecto: hubiera, habria, hubiese amado

Futuro: habré, hubiere amado

IMPERATIVO (sólo tiempos simples)

Ama, amad 


\section{INFINITIVO Y GERUNDIO}

«El infinitivo amar y el gerundio amando no deben colocarse entre los tiempos simples, porque necesitan de otra palabra que le determine». Como tiempos compuestos tenemos:

\section{INFINI'TIVO}

Pretérito: haber amado

Futuro: haber de anar

\section{GERUNDIO}

\section{Pretérito: habiendo amado}

Futuro: habiendo de amar ${ }^{1}$

En 1796 se cambian algunos detalles de la conjugación aunque la teoría general sobre los tiempos es la misma. Así, se unen bajo la denominación común de pretérito perfecto, sin distinguir entre simple y compuesto, las formas: amé, he amado y hube amado. En segundo lugar, la forma "habré amado" constituye un tiempo nuevo: el futuro perfecto de indicativo, que antes se incluia en el futuro perfecto de subjuntivo. En tercer lugar, se incluyen en el futuro perfecto de subjuntivo las formas "amare" $\mathrm{y}$ "hubiere amado", sin distinguir entre simple y compuesto. En realidad, la única diferencia es la creación. de un tiempo nuevo: el futuro perfecto de indicativo ${ }^{2}$. Como vemos, ya en el siglo xvirr encontramos un esquema de la conjugación muy similar al normal en la gramática tradicional del siglo xx.

Cierta atención dedica la Academia del siglo xvirr a la caracterización del gerundio. En I77I se define así: "Gerundio es una voz de la Cramática tomada del verbo latino gero (traigo); y se llama así porque trae consigo la significación del verbo de donde sale, como: de amar,

1 Gramditica, I77I, pp. 66-76.

- Véase Gramática, 1796, pp. 91-99. Si comparamos el sistema de I796 con el de I93r, veremos que las diferencias son menores de lo que podiamos esperar, sobre todo después de la Gramática de Bello. Estas diferencias son: creación del modo potencial, aparición del tiempo indefinido y el anterior, y la creación de una primera persona del plural en el imperativo. No entramos en el problema del modo infinitivo, que es más complicado, aunque coinciden en incluir las mismas formas. 
amando, de tener, teniendo; de partir, partiendo. El gerundio por sí solo no significa tiempo, y necesita otro verbo que le determine» ${ }^{1}$. Hay aquí un criterio significativo (no significa tiempo) junto a uno funcional (necesita otro verbo que lo determine). Más amplia es la caracterización de I796: "Entre las voces del infinitivo merece particular mención el gerundio, que es un adjetivo verbal de una sola terminación, que a veces tiene la regencia como participio, a veces se usa como absoluto, admite concordancia y significa tiempo indeterminado, esto es, el tiempo en que se puede resolver. Como es voz del infinitivo, necesita otro verbo determinante que perfeccione su sentido, como todas las voces de este modo: por ser indeclinable se acomoda sin variación alguna a los dos números, y a los géneros masculino, femenino o neutro, según la concordancia que le corresponde: $y$ en quanto a su regencia tiene la misma que el participio activo». Después hace también una relación de usos y valores ${ }^{2}$. A simple vista se aprecia el cambio experimentado. Frente a la negación de la significación de tiempo, se afirma ahora que significa tiempo indeterminado. Se introduce la característica de ser un "adjetivo verbal", con su régimen (como el participio de presente), concordancia y casos (aunque es indeclinable). Esta caracterización está más cerca del concepto latino de gerundio. Fin ambos casos se reconoce su carácter dependiente de otro verbo.

Por lo que respecta a la voz pasiva señala la Academia que él español "que no puede expresar la voz pasiva con una sola voz, se sirve de rodeo para conseguirlo». Y lo mismo se afirma en $1796^{3}$.

En I77I la «variedad de terminaciones es lo que se llama conjuga-

1 Gramática, 1771, pp. 83-84.

2 Véase Gramática, I796, pp. roo-Ior. En los diccionarios se caracteriza siguiendo un criterio significativo unido al sintáctico, y el gerundio consiste en saquella parte del verbo con que se significa la coexistencia y concomitancia de dos acciones, como leyendo me divertíl. Véase gerundio.

- Gramática, I77I, p. 88. En los diccionarios se define la pasiva como "la segunda inflexión del verbo, en que se mudan las personas a distintos casos, significando que la acción del verbo la recibe o padece la persona que entra en recto en la oración". Véase pasiva. Hoy se han puesto objeciones a la existencia de una verdadera voz pasiva en castellano, y estas objeciones llegan a poner en duda la existencia del morfema voz en nuestra lengua. Y Roca Pons, coincidiendo con la Academia del siglo XVIII, dice: "No podemos dejar de reconocer que la lengua española carece de una forma claramente definida para la expresión de la voz pasiva. Sin embargo, la oración pasiva presenta algunas características formales de otro orden, que nos permiten afirmar su existencia en la lengua, unida a un sentido pasivo indudable». Véase $o p$. cit., II, p. 4 I. 
ción" ${ }^{1}$. En 1796 la conjugación es un fenómeno que se puede incluir dentro del concepto de declinación: "Lo mismo que se llama declinación en los nombres, esto mismo se llama conjugación en los verbos, con la diferencia de que como en los nombres no es otra cosa la declinación, que la variación de su significado en fuerza de las preposiciones, sin variar la terminación, en los verbos se llama conjugación la variación que su significación admite en sus modos, tiempos, números y personas, con distintas terminaciones: correspondiendo los modos y tiempos a la declinación, y las personas a los casos de los nombres" ${ }^{2}$. Por otra parte, se distinguen las tres conjugaciones del verbo español.

Aparte de los anteriores conceptos teóricos del verbo, el principal valor de la Academia del siglo XVIII, en lo referente al verbo, está en su clasificación de irregularidades y en las normas que da para un uso correcto del verbo ${ }^{3}$. Su labor triunfa en lo que se refiere a la normativo. De todas formas, hemos visto que su esquema de la conjugación no ha sufrido demasiadas alteraciones en dos siglos.

Ya notamos que la Academia admitía el participio como una parte de la oración. Fn I77I se caracteriza así: "El participio es una parte de la oración llamado así porque en latín participa del verbo en la formación y significación, y del nombre en la declinación. Entre nosotros sólo puede llamarse participio por la participación del verbo, pero no por la declinación del nombre». Habría que haberse preguntado que si sólo participa del verbo ‘no será porque es verbo? Fin I796 se concretan más su valores y significados, quizás para darle un aire de independencia respecto al verbo que no tenía en I77I. Dice: «El participio es una parte de la oración llamada así porque participa de nombre y verbo. Participa de nombre en quanto tiene todas las propiedades de adjetivo: y de verbo en quanto significa acción, pasión y tiempo como él" ". Y sigue esta Grarrática criticando a quienes no ven una significación de tiempo en el participio. $Y$ otra vez encontramos divergencias, pues en I77I se habfa dicho: "Asf los activos como los pasivos expresan el tiempo de su acción por medio de los verbos expresos o

1 Gramática, I77I, p. 90 .

- Gramatica, I796, pp. 88-89.

- Prueba de esta preocupación por lo normativo es que la única corrección que hay en la Gramatica de 1772 respecto a la de 177 I se refiere a haber retocedo las listas de verbos irregulares, mientras lo demás permanece absolutamente igual. En 1796 también se corrigen las listas de verbos, aumentando, suprimiendo o reordenando.

4 Gramatica, 1771, p. 172; 1796, p. 2 I1. 
suplidos con que se juntan» ${ }^{1}$. Según la Gramática de I77I, el participio puede ser activo (significa acción) o pasivo (significa pasión). Además de esta clasificación significativa, la Gramática de 1796 hace otra, según el tiempo que expresan, en: de presente (obediente), de pretérito (obedecido) y de futuro, que puede ser activo (habiendo de obedecer) o pasivo (habiendo de ser obedecido) ${ }^{2}$. Es clara la tendencia de 1796 a trasladar a la gramática castellana esquemas de la gramática latina.

E1 adverbio "es una palabra que se junta al verbo para modificar y determinar su significación». En I796 se añade que es indeclinable. El adverbio solamente se une al verbo expreso o suplido, y no es cierto que se pueda unir al adjetivo, pues en este caso siempre hay un verbo suplido ${ }^{3}$. Hoy, sin embargo, la Academia admite que el adverbio se puede unir a un adjetivo o a otro adverbio ${ }^{4}$. En el siglo xvIII divide la Academia los adverbios en simples y compuestos, y éstos en adverbios que se usan en una sola palabra y adverbios que se usan en dos palabras separadas. Desde el punto de vista de su significación, se dividen en: adverbios de lugar, de tiempo, de modo, de cantidad, de orden, de afirmación, de negación y de duda. Después se dan una serie de normas sobre el uso de algunos adverbios. En I796 se repite esta doctrina ${ }^{5}$.

En I77I se caracteriza la preposición como "una palabra llamada así, porque se pone antes de otras partes de la oración». $\mathrm{Y}$ sigue: «E1 oficio de la preposición por sí sola es indicar en general alguna circunstancia que no se determina sino por la palabra que se le sigue; pero

1 Gramatica, I796, p. 214; I771, p. 173. Los diccionarios, sin embargo, no consideran el participio como parte independiente de la oración: «Es una parte del verbo que tiene las propiedades del nombre porque se declina como él: y porque tiene parte de uno y otro se llamó assín. Véase Diccionario de Autoridades, s. v. participio. Hoy se ve la relación que el participio tiene con el verbo y con el adjetivo, pero no se considera parte independiente de la oración.

2 Véase Gramática, I77I, p. I72; I796, p. 212. En I931 sólo se diferencian participios activos y pasivos; como en $\mathrm{I} 77 \mathrm{r}$. Véase p. 45.

s Véase Gramática, I771, pp. 186-187; 1796, p. 230. En el ejemplo «el hombre naturalmente bueno es fácil de engañar", el adverbio "naturalmente" va con el verbo ser suplido: "el hombre (que es) naturalmente bueno...». Definiciones semejantes se dan en los diccionarios.

- Véase Gramática, I93I, p. II9. Fue Bello el primero que aceptó la unión del adverbio al adjetivo. Véase op. cit., p. 4r.

s Véase Gramática, I77I, pp. I87-191; 1796, pp. 23I-244. En I93I la Academia hace una clasificación más amplia. Distingue calificativos y determinatitivos, después interrogativos, demostrativos y relativos, y luego hace la misma división que en el siglo XVII, suprimiendo los adverbios de comparación. Véase Gramática, 1931, pp. I19-123. 
junta ya con ella, denota la diferente relación o respeto que tienen unas con otras". Las preposiciones son: a, ante, como, con, contra, de, desde, en, entre, hacia, hasta, para, por, según, sin, sobre, tras. Seguidamente da una abundante casuística sobre sus usos y valores ${ }^{1}$. En 1796 , aun siendo sustancialmente la misma, varía la definición: «Preposición es una parte indeclinable de la oración que se antepone a otras para guiarlas y conducirlas al verdadero sentido de relación, o respeto que tienen entre sí las cosas que significan». Se suprime de la lista de preposiciones la palabra "como» ${ }^{2}$.

"Conjunción es una palabra que sirve para juntar, atar, o trabar entre sí las demás partes de la oración." Esta es la definición de I77I, señalándose más adelante que «las conjunciones no sólo sirven para unir o trabar palabras, sino también para unir unas oraciones y sentencias con otras" ${ }^{3}$. En los diccionarios, sin embargo, no se señala su función de unir oraciones ${ }^{4}$. Seis clases de conjunciones se diferencian en la Grarrática de I77r: copulativas, disyuntivas, condicionales, adversativas, causales, continuativas. Pero en 1796 se añaden dos nuevas clases: comparativas y finales. Esta adición parece claro eco de la gramática latina. También se dividen las conjunciones en simples y compuestas ${ }^{5}$.

En el siglo xvirr la Academia considera a la interjección como urra parte independiente de la oración. En I77I se dice que la interjección "es una palabra que sirve para denotar los afectos del ánimo». Y en 1796 se añade que sirve también "para llamar la atención" ${ }^{6}$. Cuando se trata

1 Véase Gramática, I77I, pp. 201-203.

2 Véase Gramática, I796, p. 246. Hoy añade la Academia a la lista de preposiciones las palabras «bajo", "cabe" y uso". Véase Gramática, I931, p. I25. El Diccionario de Autoridades dice que es la parte indeclinable de la oración que precede al nombre, a quien rige $u$ determina. Sirven también las preposiciones' para la composición o formación de algunos verbos: como anteponer, predecir, proclamar, etc.». Véase preposición. Las gramáticas, sin embargo, dicen que "las. que no se usan sino en composición, no se deben reputar como preposiciones, sino como parte de aquellas voces compuestas con ellas".

3 Gramática, I77I, pp. 222, 225. Igual caracterización se hace en I796, p. 263.

- Véase conjunción. Hoy la Academia señala la función de unir palabras $u$ oraciones como propia de la conjunción. Véase Gramática, 1931, p. 125.

- La Academia, en su Gramática de I93I, p. I26, distingue conjunciones simples y.compuestas, por su forma. Y por su significación, diferencia: copulativas, disyuntivas, adversativas, causales, consecutivas, y luego pone un metc." que no queda claro si se refiere a que hay más clases de conjunciones o a que. hay más clases de conjunciones consecutivas.

- Gramática, 1771, p. 226; 1796, p. 268. 
de la posible división de la interjección hay divergencias entre ambas gramáticas. En I77I se afirma: "Los gramáticos la dividen en clases diferentes, según los diferentes afectos que explican, y así dicen que algunas son de tristeza, otras de dolor, otras de alegría etc. pero la experiencia hace ver que una misma interjección explica diferentes afectos según la ocasión y el tono en que se profiere, o las palabras que preceden o se siguen". Por el contrario, la postura de 1796 se queda en un término medio, afirmando que "como la experiencia hace ver que una misma interjección explica diferentes afectos, no se pueden reducir algunas de ellas a clases determinadas con exactitud; aunque otras, que son de menor extensión, tienen más fixo su uso y particular significado». Acto seguido enumera las interjecciones y sus valores significativos ${ }^{1}$. En los diccionarios del siglo xviIr, después de considerar la interjección como una parte de la oración, es curioso que se cite la opinión contraria de Jiménez Patón cuando dice: "La interjección no es parte de la oración, propria ni reducida, como adelante probaremos lo uno y lo otro» ${ }^{2}$.

Como final de la primera parte de la liranática hay un capitulo dedicado a las figuras de dicción, que tienen el nombre general de «metaplasmo". "Siempre que se mudan, se quitan, o se añaden letras a una palabra es por una figura que los gramáticos llaman metaplasmo, y vale transmutación o transformación». El metaplasmo se divide en otras figuras, que son: metátesis o transposición, antítesis u oposición, sinalefa o compresión, aféresis o cortadura, síncopa o disminución, apócope o encogimiento y epéntesis o interposición ${ }^{3}$. En 1796 se suprime 1a antitesis y se añaden dos figuras más: prótesis y paragoge 4.

Pasemos ahora a dar una ojeada a lo que es la sintaxis académica en el siglo xvirr. Lo primero que observamos al ver la sintaxis dieciochesca es su desemejanza con la sintaxis tal y como se concibe hoy. Pero no cabe duda de que es superior a las sintaxis que hasta entonces se han

1 Véase Gramática, I77I, pp. 226-227; I796, pp. 268-269.

2 Diccionario de Autoridades, s. v. interjección. La Academia, en I93r, sigue considerando la interjección como parte de la oración. Véase Gramática, I93I, pp. 126-127. Sin embargo, hoy ni Gili Gaya, ni Amado Alonso, ni Roca Pons, consideran la interjección como una parte de la oración.

- Véase Gramática, 177r, pp. 228-230.

4 Véase Gramd́tica, I796, p. 272. Como resto curioso de la gramática del siglo XVIII encontramos todavia en la Gramática de la Academia de 1931, un capítulo dedicado a las figuras de dicción, y lo más curioso es que la relación de figuras coincide con la que se hace en 1796. 
escrito de la lengua castellana, por su amplitud y cantidad de observaciones, aunque a veces sea un poco farragosa ${ }^{1}$. En 177 I son tres los capítulos dedicados a la sintaxis. E1 primero trata de la sintaxis o construcción en general, y en él se define esta parte de la gramática del siguiente modo: "Esta unión, trabazón o enlace (de las partes de la oración) se llama entre los gramáticos sintaxis, o construcción, y sus reglas se reducen a declarar el orden con que deben juntarse las palabras para expresar con claridad los pensamientos». Sigue hablándonos del "orden natural de colocar las palabras, que se funda en la naturaleza misma de las cosas». Según este orden natural, el sustantivo precederá al adjetivo, el sujeto al verbo y el verbo al complemento directo y al adverbio ${ }^{2}$. En el segundo capítulo trata del régimen y construcción natural, y abarca la concordancia y todos los casos de régimen de unas palabras con otras ${ }^{3}$. El tercer capítulo es el dedicado a la construcción figurada y en él se intenta explicar por cuatro figuras todas las aparentes excepciones a las reglas anteriormente expuestas, sobre todo las del capítulo segundo. Estas cuatro figuras son: hipérbaton, elipsis, pleonasmo y silepsis. $Y$ en este punto confiesa la Academia su deuda al Brocense: "Estas quatro figuras hipérbaton, elipsis, pleonasmo y silepsis son las principales, y aun las únicas de construcción:

1 Martin Alonso hace la siguiente critica de la sintaxis de la Academia del siglo XVII: "La sintaxis académica hasta muy entrado el siglo $\mathrm{XIX}$ es pobre $\mathrm{y}$ elemental en su perspectiva aproblemática y muy poco pedagógica en sus aplicaciones. Antes de llegar al artículo de la concordancia entretiene la atención del estudioso con un inventario de palabras que rigen preposición y de preposiciones regidas. Lista farragosa, más en consonancia con los apéndices de una obra. La casuistica la envuelve como un pequeño tratado antifilosofico e impracticablen. Véase Evolución sintdctica del español, segunda edición, Madrid, Aguilar, 1964, p. 306. Si hacemos una critica de la sintaxis del siglo XVII desde un punto de vista actual, es razonable la critica de Martin Alonso. Pero si seguimos la historia de la sintaxis española, veremos en seguida la superioridad de la Academia respecto a sus antecesores, no sólo en la ordenación, sino en la criticada casuística, dada la práctica inexistencia de la sintaxis en las anteriores gramáticas.

2 Véase Gramática, I77I, pp. 232-233. Sigue la Academia ideas expresadas. ya anteriormente por Nebrija, que sigue a Quintiliano: «Entre algunas partes dela oración ai cierta orden natural i mui conforme ala razón, enel cual las cosas. que por naturaleza son primeras o de maior dignidad, se an de anteponer alas. siguientes i menos dignas: $i$ por esto dize Quintiliano que diremos de oriente a. occidente, 1 no por el contrario, de occidente a oriente, por que, según orden natural, primero es oriente que el occidente; $y$ assi diremos por consiguiente: el cielo i la tierra, el dia i la noche, la luz i las tinieblas.", op. cit., p. II7.

- Véase Gramática, I77I, p. 235. 
pues otras muchas que suelen añadirse son (como dice un célebre autor nuestro) partos monstruosos de los gramáticos» ${ }^{1}$.

La Gramática de 1796 aumenta la sintaxis en dos capítulos. Lo que en I77I se incluía en el capítulo del régimen y construcción natural se convierte en 1796 en tres capítulos: de la concordancia, del régimen de las partes de la oración y de la construcción. Y todos estos capítulos suponen un aumento considerable. Ia innovación mayor está en el capítulo del régimen. Si comparamos la sintaxis del siglo xvirr con la actual de la Academia, veremos la diferencia enorme que las separa. Pero hemos de señalar como un caso de persistencia del esquema sintáctico del siglo xviII el tratar de una sintaxis figurada frente a una sintaxis regular, incluyendo en la figurada las cuatro figuras de construcción tradicionales: hipérbaton, elipsis, pleonasmo y silepsis ${ }^{2}$. Esto es lo único que queda del siglo xvir en la actual sintaxis, siendo las diferencias mucho mayores que las coincidencias. $\mathrm{Y}$ así, mientras en el siglo xvirr se dedica una cuarta parte de la extensión a la sintaxis, hoy le dedica la Academia las tres cuartas partes de su Gramática.

\section{III}

Las fuentes, según se declara en el Prólogo de la misma Gramática, son de dos tipos: materiales elaborados por la Academia (Diccionario y disertaciones académicas) y gramáticas compuestas por autores propios y extraños. De las primeras, sobre todo del Diccionario de Autoridades, procedería la normativa que regula los usos, mientras que de las segundas serían los conceptos gramaticales más generales. Entre los gramáticos propios cita a Nebrija, Jiménez Patón y Gonzalo Correas. De los extraños no cita a ninguno ${ }^{3}$. Por otra parte, la finalidad de la Academia es pedagógica y normativa, lo que es necesario tener

1 Gramática, I77I, pp. 326-347. A pie de página cita: „Francisco Sánchez de las Brozas, en su Minerva, Lib. 4".

2 Véase Gramditica, 1931, pp. 431-436.

s Véase Gramática, I77r, prólogo. Respecto a las gramáticas que se publican en el siglo XvIr hay que notar la postura critica de la Academia, pues mientras da su opinión favorable a la reimpresión de la Gramática de Gayoso (sesión del 2 de marzo de I 769), niega su permiso para la publicación de otras gramáticas, como son unas "Instituciones Oratorias" de D. Antonio Almansa (sesión del 18 de mayo de I769) o la "Gramática Castellana" de D. Antonio Martinez Salazar, por contener muchos errores (sesión del 30 de abril de I778). 
en cuenta para explicar la poca originalidad en el campo de los conceptos gramaticales generales. Para cumplir su finalidad contó con el apoyo oficial ${ }^{1}$.

$\mathrm{Y}$ ahora veamos en qué puntos concretos principales creemos a la Academia deudora de teorías anteriores. Y empezando por el primer gramático español, Nebrija, todavía tenemos que señalar un hecho que nos ayuda a calibrar la influencia que pudo tener. Nos referimos a la noticia que se nos da en el acta del día 26 de julio de r768: "Se acordó pedir al Sr. D. Juan Iriarte todos los exemplares que haya de la Gramática de Nebrixa y que se traigan a la Academia». A la sesión siguiente D. Juan Trigueros trae 27 ejemplares más seis que se están encuadernando: " $Y$ habiéndose dado un exemplar a cada uno de los sres. que concurrieron a esta Junta, se mandaron guardar los restantes en la Academia». Es ésta una noticia significativa del valor que la Academia concede a Nebrija. Al mismo tiempo, hay que pensar en que quizás más de un académico tendría a Nebrija por guía principal. Descendiendo ahora a algunos detalles, las coincidencias más importantes entre Nebrija y la Gramática de I77 I podemos concretarlas en los siguientes puntos: caracterización de la palabra como voz o dicción; el no admitir la declinación ni los casos en la lengua castellana, punto en el que coincide también Jinuénez Patón; la definición funcional de artículo como indicador del género ${ }^{2}$. En cuanto a las coincidencias de Nebrija con las cuatro ediciones, las concretaremos en los siguientes puntos: semejanza en la caracterización de sustantivo propio y común, que Nebrija toma de Donato ${ }^{3}$; en segundo lugar, nos parece ser Nebrija el punto de partida para la diferenciación de las clases de sustantivos,

1 Lázaro Carreter cita una orden de Carlos III de I780, en la que se manda que "en todas las escuelas del reino" se enseñe "a los niños su lengua nativa por la gramática que ha compuesto y publicado la Real Academia de la Lengua, previniendo que a ninguno se admita a estudiar latinidad sin que conste antes estar bien instruido en la Gramática española", op. cit., p. I76.

2 Dice Nebrija: "Dición se llama assí, por que se dize; como si más clara mente la quisiéssemos llamar palabra", op. cit., p. 73. En cuanto a la declinación sostiene: "Declinación del nombre no tiene la lengua castellana, salvo del número de uno al número de muchos; pero la significación delos casos distingue por preposiciones", pp. 88-89. Su caracterización del artículo consiste en que use an de llamar artejos aquellos nessos de que se componen los dedos; los cuales son unos pequeños miembros a semejança de los cuales se llaman aquellos artículos, que añadimos al nombre para demostrar de qué género es", p. 94.

- Por su calidad distingue Nebrija: "Proprio nombre es aquel que conviene a uno solo, como César, Pompeio. Común nombre es aquel que conviene a muchos particulares, que los latinos llaman apelativon, p. 74 . 
pues, aunque no coinciden plenamente, de todas las anteriores es la de Nebrija la división que más se acerca ${ }^{1}$; una tercera coincidencia es la distinción del pronombre como parte independiente de la oración, distinción que no hacen ni Correas ni Patón ${ }^{2}$. Nos parece ver en Nebrija, junto con Correas, la base de la división de los tiempos del verbo, aunque tampoco en este caso haya plena coincidencia ${ }^{3}$. Concuerdan también Nebrija y la Academia en negar que haya una forma especial para la pasiva en castellano, teniendo que recurrir a una perífrasis. Por fin, señalaremos que Nebrija, frente a Correas y Patón, coincide con la Academia en considerar el participio como parte independiente de la oración ${ }^{4}$. Vemos cómo en la cuarta edición disminuyen las relaciones de Nebrija y la Academia.

Las huellas de Jiménez Patón en la Gramática de la Academia del siglo xvirr no son tan numerosas como las de Nebrija o Correas y desde luego son menores de lo que puedan ser en el Diccionario de Autoridades, donde es raro el artículo dedicado a un término gramatical en que no es citado ${ }^{5}$. De todas formas, podemos señalar como coincidencia entre Patón y la Gramática de I77I el no admitir ni la declinación ni los casos. En 1796 se distinguen los mismos géneros que diferenciaba Patón (masculino, femenino, neutro, común de dos, ambigua y epiceno) ${ }^{6}$. Coincide además Patón con tódas las ediciones del siglo xvirI en dos puntos:

1 Nebrija distingue entre primogénito y derivado, y dentro de los derivados diferencia ocho clases: patronimicos, posesivos, diminutivos, aumentativos, comparativos, verbales, participiales y adverbiales. Más adelante une derivados y denominativos, e incluye en los denominativos los patronimicos, posesivos, diminutivos, aumentativos y comparativos. Véase op. cit., pp. 77-8o.

- Véase op. cit., p. 92.

2 Nebrija distingue cinco tiempos: presente, pasado no acabado, pasado acabado, pasado más que acabado y venidero. Véase op. cit., p. 98.

- Véase op. cit., pp. 99 y 103.

- Esta influencia de Patón en el Diccionario de Autoridades ha sido estudiada por Quilis y Rozas en la edición crítica de su obra: BARTOLOME JIMÉNEz PATón, Epitome de ortografia latina y castellana. Instituciones de la Gramática Española. (Estudio de Antonio Quilis y Juan Manuel Rozas), "Clásicos Hispánicos», Madrid, C. S. I. C., 1965.

- Dice Jiménez Patón: «Caso es la cayda y terminación de la dición... Las lenguas que desto carecen se ayudan para variar las dicciones (como diximos) de las preposiciones... De aqui se sigue que como no tienen variedad, no constituyen diferentes declinaciones, porque sólo en el recto o nominativo tienen sus diferencias, $y$ en las terminaciones diferentes son tantas y más que en Latín, op. cit., p. 97. 
la concepción de los modos del verbo y la negación de una forma especial para la pasiva, como Nebrija ${ }^{1}$.

Más notable que la influencia de Patón nos parece la de Gonzalo Correas. El parentesco entre la Gramática de I77I y Correas se puede ver en la concepción del género. Ambas gramáticas admiten masculino y femenino, pues aunque Correas nos habla también del neutro, a renglón seguido dice que el neutro reside en el artículo, quedando como verdaderos géneros el masculino y el femenino. $\mathrm{Y}$ dentro de la concepción del género, coinciden además en negar la posibilidad de dar reglas para conocer el género de los nombres por su significación o por su terminación ${ }^{2}$. Estas reglas se darán en 1796 . Otro punto en el que Correas parece ser la fuente de I77I es el que se refiere a la definición del adjetivo. Aunque todos los caracteres que se señalan ya habian sido notados anteriormente, esto se había hecho separadamente y no dispuestos de la forma en que lo son por Correas y la Gramática de $177 \mathrm{I}^{\mathbf{3}}$. Por último, señalemos cómo la Gramática de $177 \mathrm{I}$ sigue parcialmente a Correas en su caracterización del verbo. De Correas toma, en efecto, el que el verbo signifique acción o pasión, al tiempo que elimina los elementos morfológicos que Correas introduce en su definición del verbo 4. El principal punto de contacto entre Correas y la Gramática de 1796 es el que se refiere a la declinación. Ambas gramáticas aceptan, en efecto, la existencia de declinación en castellano. Otro punto de contacto entre Correas y 1796 es la mezcla de características morfológicas y significativas en la definición del verbo. Similitudes de Correas con las cuatro ediciones de la Gramática de la Academia del siglo xvirI son: criterio lógico-sintáctico en la definición del sustantivo; semejanza en la división de los pronombres, aunque la Academia es superior en claridad; junto con Nebrija, Correas ofrece la base para la división de los tiempos del verbo; señalar como función de las conjunciones el unir palabras y oraciones; la división de las conjunciones de Correas es la

1 Patón afirma: «Los modos son según los adverbios, mas los más comunes son quatro: indicativo, imperativo, conjuntivo, infinitivo. $Y$ aun a éste, mejor le dixéramos sin modo, pues no letiene con determinación y certeça, mas este es su modo, no tenerlen, op. cit., p. Ior.

- Véase Gonzalo Correas, Trilingüe de tres artes de las tres lenguas Castellana, Latina i Griega..., Salamanca, Antonio Ramirez, 1627, p. 13.

- Dice Correas que adjetivo es uel nombre que sinifica calidad, 1 propiedad alguna, que se añade al sustantivo... I no puede estar en la orazión sin sustantivo, i a de conzertar con él en género, número, 1 cason, op. cit., p. 26.

- Define Correas el verbo asi: «Verbo es aquella palavra, que significa el hazer i obrar, $i$ dezir las cosas, $i$ ser dichas $i$ hechas: $i$ tiene boz $i$ conjugazionn, op. cit., p. 66. 
que más se aproxima a la de la Academia ${ }^{1}$. Correas comparte con Nebrija la primacía en lo que se refiere a las influencias en la Academia del Xvirr. Y hemos de notar que es el autor más seguido en las divisiones que se hacen de cada una de las partes de la oración.

Sin que afirmemos un conocimiento directo de la "Gramática" de Port-Royal por parte de la Academia, hay algún detalle evidente en que coincide con esta gramática francesa. Con relación a la Gramática de I77r los más claros son: el señalar la afirmación como una de las características del verbo. La Academia, con su criterio acumulativo de características en la definición del verbo, señala también la afirmación como una de ellas. El P. Benito de San Pedro señalaba la afirmación como nota significativa del verbo y de este autor pudo tomarlo la Academia ${ }^{2}$. Por otra parte, el esquema de la sintaxis propuesto por la "Gramática" de Port-Royal es el que se desarrolla en la Graniática académica de $177 \mathrm{r}^{3}$. Otros detalles en que hay coincidencia entre PortRoyal y la Academia del siglo xvir son: distinguir las mismas nueve partes de la oración, punto en el que coinciden también Juan de Miranda, Pedro Contaut y Gayoso; la división de los tiempos del verbo en simples y compuestos; y el señalar las mismas figuras dentro de la sintaxis figurada, cuya fuente común puede ser el Brocense ${ }^{4}$. No podemos, pues, afirmar un conocimiento directo de la "Gramática" de Port-

1 La definición que da Correas de sustantivo es: "Sustantivo es el nombre, que sinifica sustanzia corporal, o sin cuerpo, i puede estar por sí solo en la orazión como zielo, mar, tierra, onbre, Pedro, Maria, aire, dolor, virtud", op. cit., p. 25. Distingue Correas pronombres demostrativos, relativos, interrogativos, indefinitos o indeterminados. Los personales son los que llama demostrativos de primera persona común a los dos géneros en manera sustantiva. Véase op. cit., pp. 2829. Correas diferencia cinco tiempos: presente, imperfecto, perfecto, pluscuamperfecto y futuro. Véase p. 67. Tiene por conjunción una partezilla, que xunta partes, $i$ oraziones, $i$ por este xuntar se llama ansí. Las clases de conjunciones son: copulativas, disyuntivas, causales, condicionales y continuativas. Sólo hay qua añadir las adversativas para tener todas las clases de la Academia. Véase op. cit., pp. ro7-ro8.

2 Port-Royal define el verbo como wun mot dont le principal usage est de signifier l'affirmation", op. cit., p. 95. Y el P. Benito de San Pedro dice que "el verbo es una palabra o parte de la oración cuyo oficio principal es significar la afirmación o juicio que hacemos de las cosasm. Cf. LAzaro CARRETER, op. cit., p. 188.

3 El esquema sintáctico de Port-Royal abarca dos partes: I Construcción natural (que contiene concordancia y régimen). II Figuras de construcción: silepsis, elipsis, pleonasmo e hipérbaton. Véase $o p$. cit., pp. I53-r6o. Sobre este mismo esquema se construye la sintaxis académica del siglo XVIr.

- Véase op. cit., pp. 30, 108-III y 160. 
Royal por parte de la Academia, sino solamente señalar estas coincidencias que quizás se deban a conocimiento indirecto.

Hay otros gramáticos con los que la Academia tiene alguna opinión común. Tal es el Brocense, con quien concuerda la Gramática de I77I en dividir la gramática en dos partes: morfología y sintaxis. La edición de 1796 está de acuerdo con el Brocense en diferenciar un gerundio propiamente verbal de otro que funciona como un participio. Por último, es el Brocense el autor en quien se inspira la Academia dieciochesca para su sintaxis figurada, con las mismas cuatro figuras de construcción (recordemos la cita que se le hace en I77I) ${ }^{1}$.

Juan de Miranda es otro gramático con cuya obra tiene la Gramática académica puntos de contacto. Igual que la Gramática de 1796 divide Juan de Miranda las palabras en variables e invariables. Por otra parte, diferencia las mismas nueve partes de la oración ${ }^{2}$. Se sitúa 1a Academia junto al P. Juan de Villar al señalar como función de la conjunción el unir palabras y oraciones ${ }^{3}$.

Vemos, pues, que la Academia no está aislada de la doctrina gramatical anterior. No hemos pretendido ser exhaustivos, sino of recer una muestra de esta unión de la Academia con una tradición gramatical. Esto se da en mayor medida en el aspecto teórico gramatical. Pues es en lo normativo donde la Academia del siglo xvirr brilla por su originalidad y donde supera con mucho a todos los gramáticos anteriores. Hemos visto que ella es consciente de esta finalidad de su obra y por eso cuando en alguna ocasión plantea una discusión teórica casi siempre 1a soluciona diciendo que poco aprovechan estas discusiones para un mejor conocimiento de la gramática. Su valor para la gramática normativa se ve, por ejemplo, en la división de los pronombres o de los adverbios, que siguen teniendo validez en la gramática tradicional de hoy. $O$ en la sistematización, más clara y semejante a la actual, de los tiempos de la conjugación. O sus listas de verbos irregulares y abundante casuística, propia para la consulta de la norma. Estamos de acuerdo, pues, con Lázaro Carreter cuando dice, enjuiciándola dentro del panorama gramatical del siglo xvirr: "La Gramática de la Academia es muy superior, como compendio y ordenación de doctrinas anteriores, y es éste el valor que posee en la Historia Gramatical española» ${ }^{4}$.

1 Véase Constantino Garcf $f_{A}$, op. cit., pp. 60-6i y 134-r35.

2 Véase JUAN DE MURANDA, Osservationi della lingua castigliana, Venegia, 1566, p. 12.

3 Véase P. JuAn VIrI,AR, S. J., Arte de la lengua española, Valencia, Francisco Verengel, $165 \mathrm{I}$, p. 57.

- $O p$. cit., pp. r8r-r82. 
No podemos dejar de citar, por clarividente y relativamente cercano a la época que estudiamos, el juicio de Vicente Salvá: "La (Gramática) de la Real Academia española, publicada la primera vez en el año I77I, atendió con bastante particularidad a los idiotismos, esplicados mui de propósito en la lista de las preposiciones que rigen ciertos nombres $\mathrm{y}$ verbos y por incidencia en otros varios lugares. Esta parte de aquella gramática, la esplicación de algunos tiempos y de la armonía que guarda el verbo determinante con el determinado, y varias otras observaciones, no menos juiciosas que delicadas, manifiesta que confió desde luego su redacción a sujetos hábiles, y que también lo han sido los que han cuidado sucesivamente de todas las ediciones hasta la cuarta. Mas los sabios que han pertenecido en los sesenta años últimos a aquel cuerpo, distraídos por tareas más gratas y de mayor gloria, o faltos de constancia para reducir a reglas los principios del lenguaje que tan bien han sabido observar en la práctica, no han llenado hasta hoy los muchos vacíos de su gramática» ${ }^{1}$. Otra vez se alaba su valor normativo.

Junto a su poca originalidad teórica y su gran valor normativo, salta a la vista, por el breve estudio hecho de las ideas gramaticales académicas del siglo xviIr, que no hay unanimidad teórica entre los distintos cuerpos doctrinales de la Academia. Y a este respecto se diferencian claramente tres grupos: los diccionarios, con alguna breve diferencia entre ellos; la Gramática de I77I, que creemos más enraizada en la tradición gramatical española; y la Gramática de I796, donde apreciamos importantes cambios que apuntan en una dirección latinizante, olvidando algo la sana tradición gramatical de Nebrija, Patón, Correas o el Brocense.

No queremos terminar sin hacer notar las curiosas reminiscencias del siglo xvirr que todavía se pueden apreciar en la Gramática académica de I93I: tratar de una sintaxis figurada, con las mismas figuras de construcción que en el siglo xvirr, y el hablarnos de figuras de dicción. Esto tendría más propio lugar en una retórica. Pero la tradición deja sentir su peso todavía.

Por fin, hay que hacer constar que con la Graniática de la Academia del siglo xvirI se inaugura un tipo de estudios gramaticales de carácter normativo-práctico, que ha sido la base casi exclusiva de la formación gramatical hasta nuestros días y que todavía comparte esa labor en gran medida con las corrientes más modernas de la gramática.

\section{Josf́ Domf́nguez Caparrós}

1 Véase MANuer MoURELIIE-LEMA, La teoria lingüistica en la España del siglo XIX, Madrid, Prensa Española, 1968, p. 379. 